\title{
Characterization of ovine herpesvirus 2-induced malignant catarrhal fever in rabbits
}

\author{
Hong Li ${ }^{\text {a,* }}$, Cristina W. Cunha ${ }^{\text {a }}$, Katherine L. Gailbreath ${ }^{\text {a,b }}$, Donal O’Toole ${ }^{\text {, }}$, \\ Stephen N. White ${ }^{\mathrm{a}, \mathrm{b}}$, Alain Vanderplasschen ${ }^{\mathrm{d}}$, Benjamin Dewals ${ }^{\mathrm{d}}$, \\ Donald. P. Knowles ${ }^{\mathrm{a}, \mathrm{b}}$, Naomi S. Taus ${ }^{\mathrm{a}}$ \\ a Animal Disease Research Unit, USDA-Agricultural Research Service, 3003 ADBF, Washington State University, Pullman, WA 99164-6630, USA \\ ${ }^{\mathrm{b}}$ Department of Veterinary Microbiology and Pathology, Washington State University, Pullman, WA 99164, USA \\ ${ }^{\mathrm{c}}$ Wyoming Veterinary Diagnostic Laboratory, University of Wyoming, Laramie, WY 82071, USA \\ ${ }^{\mathrm{d}}$ Department of Infectious and Parasitic Diseases, Immunology-Vaccinology (B43b), Faculty of Veterinary Medicine, University of Liege, B-4000 Liege, Belgium
}

\section{A R T I C L E I N F O}

\section{Article history:}

Received 10 November 2010

Received in revised form 26 January 2011

Accepted 14 February 2011

\section{Key words:}

Malignant catarrhal fever

Ovine herpesvirus 2

Rabbit model

Lymphoproliferation

Gene expression

\begin{abstract}
A B S T R A C T
Malignant catarrhal fever (MCF) is a frequently fatal lymphoproliferative disease syndrome primarily of ruminant species, caused by gammaherpesviruses in the genus Macavirus. Ovine herpesvirus 2 (OvHV-2), carried by sheep, causes sheep-associated MCF worldwide, while Alcelaphine herpesvirus 1 (AlHV-1), carried by wildebeest, causes wildebeest-associated MCF, mainly in Africa. Diseases in rabbits can be induced by both viruses, which are clinically and pathologically similar; however, recent studies revealed different expression of viral genes associated with latency or lytic replication during clinical disease between the two viruses. In this study, we further characterized experimentally induced MCF in rabbits by nebulization with OvHV-2 from sheep nasal secretions to elucidate the course of viral replication, along with in vivo incorporation of 5Bromo-2'-Deoxyuridine (BrdU), to evaluate lymphoproliferation. All six rabbits nebulized with OvHV-2 developed MCF between 24 and 29 days post infection. OvHV-2 DNA levels in peripheral blood leukocytes $(\mathrm{PBL})$ remained undetectable during the incubation period and increased dramatically a few days before onset of clinical signs. During the clinical stage, we found that predominantly lytic gene expression was detected in PBL and tissues, and both $\mathrm{T}$ and $\mathrm{B}$ cells were proliferating. The data showed that the viral gene expression profile and lymphoproliferation in rabbits with OvHV-2 induced MCF were different from that in rabbits with AlHV-1 induced MCF, suggesting that OvHV-2 and AlHV-1 may play a different role in MCF pathogenesis.
\end{abstract}

Published by Elsevier B.V.

\section{Introduction}

Malignant catarrhal fever is a frequently fatal, lymphoproliferative disease syndrome of many species in the Artiodactyla order, including cattle, bison, and deer, as well as pigs (Russell et al., 2009), caused by gammaherpesviruses in the genus Macavirus (Davison et al., 2009). Although several viruses in the MCF virus group are

\footnotetext{
* Corresponding author. Tel.: +1 509335 6002, fax: +1 5093358328 E-mail address: hli@vetmed.wsu.edu (H. Li).
}

capable of inducing the disease (Li et al., 2005), the most important members in this group are Alcelaphine herpesvirus 1 (AlHV-1) and ovine herpesvirus 2 (OvHV-2) (Russell et al., 2009). AlHV-1 is carried by blue and black wildebeest and the induced disease is called wildebeest-associated MCF (WA-MCF) (Plowright, 1990). OvHV-2 is carried by sheep worldwide and the disease is called sheep-associated MCF (SA-MCF) (Plowright, 1990). WA-MCF is an important economic concern to cattle populations in parts of Africa where they share grazing with wildebeest (Bedelian et al., 2007), and has also caused losses in zoological collections and game farms where wildebeest 
are present (Blake et al., 1990; Meteyer et al., 1989). SAMCF is the leading cause of death of ranched American bison and has been associated with numerous outbreaks due to their high susceptibility (Li et al., 2006; Schultheiss et al., 2000). SA-MCF is also economically important in other farmed ruminant species including Bali cattle in Indonesia (Daniels et al., 1988; Wiyono et al., 1994) and red deer in New Zealand (Audige et al., 1994; Orr and Mackintosh, 1988), as well as causing sporadic problems for many domestic and wild ruminants worldwide (Heuschele, 1988). Rabbits develop an MCF-like disease following experimental infection with either OvHV-2 or AlHV-1 (Buxton and Reid, 1980) and are used as an animal model to study AlHV-1 induced MCF pathogenesis (Dewals et al., 2008). Experimentally induced MCF in rabbits with OvHV-2 by nebulization was successful (Gailbreath et al., 2008) and its usefulness as a model that involves a natural mode of transmission to study certain features of infection and disease has been under investigation, which is the purpose of this study.

A striking feature of MCF is the species-specific nature of the disease. Generally, clinical disease in susceptible species is associated with some combination of lymphoid hyperplasia, arteritis-phlebitis, abomasitis (or gastritis), enteritis-colitis-typhilitis, panophthalmitis, cystitis, hepatitis, and encephalitis (Liggitt and DeMartini, 1980a,b). American bison with natural or experimentally induced MCF due to OvHV-2 generally have modest lesions in lymph nodes and blood vessels (O'Toole et al., 2007). The most consistent and severe lesions in bison are inflammation and ulceration in the digestive tract, particularly in the oral cavity, esophagus, forestomachs, abomasum, cecum and colon. Hemorrhagic cystitis is almost invariably found in bison when clinical signs develop. Urothelium in the renal pelvis, ureter and urethra is degenerated and/or sloughed (O'Toole et al., 2002, 2007). Necrotizing arteritis, which is such a characteristic feature of MCF in many ruminant species, is inconspicuous.

The pathogenesis of MCF induced by either AlHV-1 or OvHV-2 is not well understood. Although both viruses are closely related antigenically and genetically, causing a similar disease syndrome and lesions (Plowright, 1990), increasing evidence indicates that there are significant differences between OvHV-2 and AlHV-1 in several aspects, including infection and shedding from natural hosts, the requirements for in vitro propagation, and expression of viral genes responsible for lytic replication in clinically affected hosts. Shedding patterns differ between natural hosts: infected sheep shed the virus sporadically with a short-lived episode, more frequently between 6 and 9 months of age (Li et al., 2004), and newborn lambs are not the source of infection (Li et al., 2004). By contrast, most newborn wildebeest calves are infected and shed virus continuously until 3-4 months of age, and are the primary virus source for transmission (Mushi et al., 1981). Cell tropisms are different between the two viruses: AlHV-1 readily grows in various cell lines (Plowright, 1990) and infection can be induced in cattle or rabbits by cell-free virus through various routes, including intranasally, intramuscularly and intravenously (Haig et al., 2008; Mushi, 1980). In contrast, OvHV-2 has not been propagated in vitro yet, even in cell lines that can support AlHV-1 in vitro propagation. Cell-free OvHV-2 from sheep nasal secretions failed to induce infection in sheep following intravenous or intraperitoneal inoculation (Li et al., 2008). Recent studies revealed that the transcripts of the open reading frame (ORF) 25, a gene encoding the major capsid protein, were present in virtually all the tissues of cattle, bison (Cunha et al., 2007) and rabbits (Gailbreath et al., 2008) with OvHV-2-induced MCF, but not present in the tissues (spleen and lymph nodes) of rabbits with AlHV-1induced MCF (Dewals et al., 2008), suggesting that viral infection at the tissue level in clinically susceptible hosts may also be different. In this study, we experimentally induced MCF in rabbits by intranasal inoculation of OvHV2 from sheep nasal secretions to determine: (1) if rabbits can be a reliable model for OvHV-2-induced MCF; (2) viral replication status based on viral gene expression; and (3) lymphoproliferation based on in vivo incorporation of 5-Bromo-2'-Deoxyuridine (BrdU).

\section{Materials and methods}

\subsection{Rabbits and experimental infection}

A total of 10 four-month-old New Zealand white rabbits were obtained from the Western Rabbits Company of Oregon and maintained at Washington State University, Pullman, WA in accordance with an approved animal care and use protocol. The rabbits were individually caged and held in the same isolation room. After an acclimation period of one week, each rabbit was given three consecutive daily doses of $5 \mathrm{mg} / \mathrm{kg}$ enrofloxacin (Baytril) by intramuscular injection into the caudal thigh muscles to prevent infection by potential bacterial pathogens present in the sheep nasal secretions. The rabbits were divided into two groups: a test group $(n=6)$ and a negative control group $(n=4)$. The nasal secretion inoculum used in this study was the same pooled inoculum used in a previous rabbit study (Gailbreath et al., 2008). Each rabbit in the test group was inoculated by nebulization with $2 \mathrm{ml}$ of pooled sheep nasal secretions containing $10^{7}$ OvHV-2 DNA copies using the same procedure described previously (Gailbreath et al., 2008). The rabbits in the negative control group each received $2 \mathrm{ml}$ of nasal secretions collected from OvHV-2 negative sheep. The nebulization procedure was carried out in an operation room, which was separated from the rabbit holding room. The nebulization for the negative control group was carried out first, and then for the positive group. All the rabbits were observed daily, including monitoring body temperatures, and were euthanized within $48 \mathrm{~h}$ of the onset of pyrexia $\left(>104^{\circ} \mathrm{F}\right)$.

\subsection{Sample collection and preparation}

Two milliliters of EDTA-anticoagulated blood from an aural vein of each rabbit was collected twice a week. Blood samples were prepared for testing for MCF viral antibody by competitive ELISA (cELISA), OvHV-2 DNA by nested PCR, and incorporation of BrdU in lymphocytes (after 20 days post infection, DPI) by flow cytometry. Additional $20 \mathrm{ml}$ blood samples were collected before euthanasia, and the buffy 
coat cells were purified by ficoll gradient centrifugation for flow cytometry, and the remaining cells were diluted in TRIzol reagent (Invitrogen) and stored at $-80^{\circ} \mathrm{C}$ for RNA analysis. Euthanasia was carried out by intramuscular injection of ketamine and xylazine followed by an intravenous overdose of pentobarbital. Necropsies were performed on all euthanized rabbits, and samples of lung, mesenteric lymph nodes, liver, spleen and bladder were collected. Portions of each sample were snap frozen in liquid nitrogen and stored at $-80^{\circ} \mathrm{C}$ for RNA and DNA analyses, and portions were fixed in neutral buffered formalin and embedded in paraffin blocks. Hematoxylin and eosin stained slides were prepared from the paraffin blocks by standard techniques. Samples of mesenteric lymph node and spleen collected from the two rabbits euthanized at 29DPI were prepared for single cell suspensions and followed by gradient centrifugation for flow cytometry using a previously described protocol (Davis and Hamilton, 2008).

Plasma from EDTA - blood samples was collected for the MCF viral antibody assay and stored at $-20^{\circ} \mathrm{C}$ for later use. Total DNA for PCR assays was extracted from peripheral blood leukocytes (PBL) and tissues using the FastDNA kit (QBiogene) as described by the manufacturer. Total RNA for reverse transcription (RT)-PCRs was extracted from PBL and tissues $(50 \mathrm{mg})$ using iPrep ${ }^{\mathrm{TM}}$ TRIzol ${ }^{\mathbb{R}}$ Plus RNA Kit and the iPrep instrument (Invitrogen) as described by the manufacturer but including a DNase treatment step. Total RNA was quantified using the Quant$\mathrm{iT}^{\mathrm{TM}} \mathrm{RNA}$ assay kit and a Qubit ${ }^{\mathbb{R}}$ fluorometer (Invitrogen) and its integrity assessed by analysis of rRNA on agarose gel. The absence of DNA contamination in each RNA sample was confirmed by PCR without the reverse transcriptase enzyme (HotStarTaq Plus Master Mix, Qiagen) targeting a rabbit reference gene (YWHAZ) and OvHV2 ORF 25 . Immediately following extraction, $1 \mu \mathrm{g}$ of RNA was converted into cDNA using the SuperScript ${ }^{\circledR}$ VILO $^{\mathrm{TM}}$ cDNA Synthesis Kit (Invitrogen) according to the manufacturer's recommendations and stored at $-20^{\circ} \mathrm{C}$ until further use.

\subsection{In vivo incorporation of BrdU and immunofluorescent staining}

All rabbits were injected intravenously daily with BrdU $(25 \mathrm{mg} / \mathrm{kg})$ starting on 20 DPI. The cells that had incorporated BrdU in peripheral blood, lymph nodes and spleen were counted and immunophenotyped by flow cytometry as previously described (Davis and Hamilton, 2008). Briefly, $100 \mu \mathrm{l}$ whole blood (or Accu-paque-isolated lymphocytes from lymph nodes or spleen) per well in a 96-well plate was incubated on ice for $15 \mathrm{~min}$ with a primary antibody against rabbit pan-T cell (RTH26A), CD8 (ISC27A), B-cell (MRB29A), monocytes/basophils (MRB120A) from the Washington State University monoclonal antibody center, or CD4 (KEN-4) (Serotec). The cells were washed and incubated on ice for $15 \mathrm{~min}$ with the appropriate fluorescent-conjugated secondary goat antimouse antibody (Caltag and Southern Biotech). After washing, red blood cells (RBC) were lysed using RBC lysis buffer ( $200 \mu \mathrm{l} /$ well on ice for $10 \mathrm{~min}$ ) (Becton Dickson).
The washed cells were then ready to be labeled with FITCanti-BrdU antibody using BD Pharmingen FITC BrdU Flow Kit based on the recommendation of the manufacturer (BD Biosciences). The immunophenotyped cells were fixed and permeabilized with BD Cytofix/Cytoperm buffer at room temperature (RT) for $20 \mathrm{~min}$ (on a shaker). After being washed and treated with Cytoperm Plus buffer and Cytofix/Cytoperm buffer on ice for $10 \mathrm{~min}$ and $5 \mathrm{~min}$, respectively, the cells were suspended in $100 \mu \mathrm{l} /$ well of DNase (at $300 \mu \mathrm{g} / \mathrm{ml}$ in sterile PBS), and incubated for $1 \mathrm{~h}$ at $37^{\circ} \mathrm{C}$. After additional washes, BrdU staining was then performed by incubation with $50 \mu \mathrm{l} /$ well of diluted FITCanti-BrdU at RT for 30 min on a shaker. After the final wash, the stained cells were resuspended in wash buffer and ready for flow cytometry analysis (Becton Dickson). Flow cytometric data were analyzed using the $t$-test procedure of SAS 9.2 (SAS Institute) on percentages transformed with Anscombe's improved arcsine transformation (Anscombe, 1948) and significance was based on nominal $p$ value $<0.05$.

\section{4. cELISA, nested PCR, real-time $P C R$, and real-time RT-PCR}

Competitive ELISA based on a monoclonal antibody (MAb-15) against an epitope conserved among all MCF viruses examined to date ( $\mathrm{Li}$ et al., 1994) was used to detect MCF viral antibodies. The protocol for the cELISA was described previously (Li et al., 2001). A nested PCR and a real-time PCR were used to detect and quantify, respectively, OvHV-2 DNA. Both assays were described previously (Baxter et al., 1993; Li et al., 1995; Traul et al., 2007) and use different primer sets targeting the same region of OvHV-2 ORF75. Amplification of rabbit cellular gene (YWHAZ) was used to ensure that cDNA was present in an adequate quality. Primers to amplify ORF 25 (forward 5'-3': gcctcctgcgtggtctcta; reverse 5'-3': ttcagcatctcctccttgttg) and ORF 50 (forward $5^{\prime}-3^{\prime}$ : gtctctccctacagttctt; reverse $5^{\prime}-3^{\prime}$ : gacccaacatcagtagac) were designed using Primer3 v. 0.4.0 (http://frodo.wi.mit.edu/) and Vector NTI (Invitrogen). The specificity of the primers was confirmed by gel electrophoresis and sequencing of the PCR products. The set of primers used to amplify ORF73 and YWHAZ were previously described (Mamo et al., 2008; Meier-Trummer et al., 2009a). Nucleic acid amplification and detection of all genes were performed using a CFX96 ${ }^{\mathrm{TM}}$ real-time PCR Detection System (Bio-Rad). The reactions were carried out in a $20 \mu \mathrm{l}$ volume containing $1 \mathrm{X}$ SSoFast ${ }^{\mathrm{TM}}$ Evagreen $^{\mathrm{B}}$ Supermix (Bio-Rad); $200 \mathrm{nM}$ of each forward and reverse primer; and $2 \mu \mathrm{l}$ of cDNA diluted at 1:20. The cycling reactions consist of an initial denaturation of $95^{\circ} \mathrm{C}$ for $30 \mathrm{~s}$ followed by 40 cycles of $95^{\circ} \mathrm{C}$ denaturation for $15 \mathrm{~s}$ and $60^{\circ} \mathrm{C}$ annealing/extension for $45 \mathrm{~s}$ with a plate read after each cycle. Melting curve analysis followed all PCR runs to confirm the specificity of the amplicons and was performed from 65 to $95^{\circ} \mathrm{C}$ with an increment of $0.5{ }^{\circ} \mathrm{C}$ for $5 \mathrm{~s}$ followed by a plate read. A non-template control using water instead of cDNA was included for each target gene in all runs and all samples were tested in duplicate. Results were analyzed by the CFX Manager Software (Bio-Rad). 


\section{Results}

\subsection{Malignant catarrhal fever induced in rabbits by nebulization of OvHV-2}

All 6 rabbits nebulized with sheep nasal secretions containing OvHV-2 developed clinical signs, including apathy, adipsia, anorexia, and hyperthermia at $27.16 \pm 1.83 \mathrm{DPI}$, and were euthanized from 24 to $29 \mathrm{DPI}$ (Fig. 1A). Five out of six infected rabbits had detectable antibody at $25 \mathrm{DPI}(n=3)$ and $28 \mathrm{DPI}(n=2)$, respectively (Fig. 1B). All four rabbits were negative for MCF viral antibody at all sampling time points by cELISA (data not shown). OvHV-2 DNA was detected by real-time PCR in PBL of all 6 rabbits between 17 and 24 DPI (Fig. 1C). At necropsy, all infected rabbits had splenomegaly and generalized lymphadenopathy as expected. The liver of all infected rabbits had multifocal, pinpoint, tan-colored foci scattered randomly throughout. Histologically, the most consistent lesions were present in lymphoid tissues, lung and liver. There was moderate diffuse lymphadenitis with progression to granulomatous lymphadenitis in more severe lesions. Lymphoid necrosis was a feature in gut-associated lymphoid aggregates. Pulmonary lesions consisted of interstitial pneumonia with intralesional phlebitis-arteritis. Hepatic lesions were moderate to severe, and comprised essentially of diffuse portal hepatitis with cholangitis, expansion into periacinar hepatic parenchyma, hepatic necrosis, and portal phlebitisarteritis. Larger hepatic lesions were overtly granulomatous. Neither OvHV-2 DNA nor MCF lesions were detected in any of the four rabbits in the negative control group.

\subsection{Proliferation of $T$ and $B$ cells in peripheral blood and tissues of rabbits with OvHV-2 induced MCF}

One of the goals in the study was to determine whether there was increased lymphocyte proliferation in infected rabbits compared to the controls, and which subtype of lymphocytes was proliferating. The cell proliferation was detected by measuring in vivo incorporation of BrdU in the proliferating cells. BrdU incorporation and lymphocyte phenotypes were detected by dual immunofluorescent staining and flow cytometry analysis. After daily intravenous injection of BrdU starting at 20 DPI, the percentage of BrdU-positive cells in peripheral blood increased gradually in all subtypes of cells without significant difference between infected and negative control groups until 29 DPI. Analysis of blood samples from infected rabbits $(n=2)$ compared with negative controls $(n=4)$ at 29 DPI revealed that there was a significant difference in the percentage of BrdU-positive cells co-labeled with antibodies specific for pan-T cells, CD4+, and CD8+ cells, but not with monocytes and B-cells (Fig. 2A). In analysis of cells obtained from mesenteric lymph nodes and spleen, the percentage of BrdU-positive cells was significantly higher in Pan-T cell, B-cell, and monocytes only found in spleen from the OvHV2 infected group compared to the negative control (Fig 2B). The data for analysis of the proliferating cells in spleen and mesenteric lymph nodes from the rabbits euthanized before 29DPI were not available due to mismatched negative controls. Taken together, the results suggested that besides CD8+ cells, other cells, including CD4+ and B
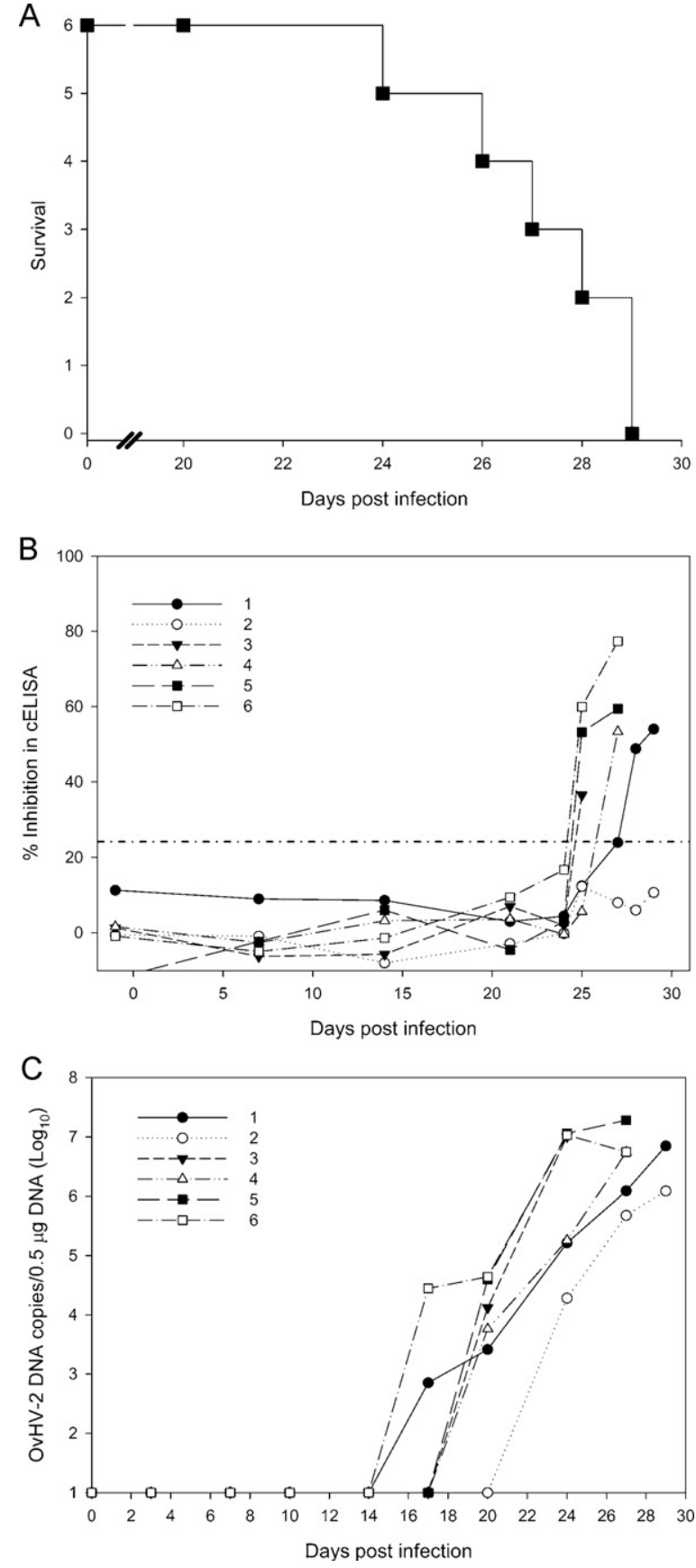

Fig. 1. Malignant catarrhal fever induced by nebulization of OvHV-2 in rabbits. (A) Cumulative incidence survival curve of the rabbits experimentally infected with OvHV-2. At day 0 , all rabbits were intranasally nebulized with OvHV-2 in sheep nasal secretions $\left(10^{7}\right.$ DNA copies). Starting at 20 days post infection, all rabbits were injected intravenously daily with $\operatorname{BrdU}(25 \mathrm{mg} / \mathrm{kg})$ until the end of the experiment. (B) MCF viral antibody detected by cELISA in plasma of the rabbits experimentally infected with OvHV-2. The dotted line indicates percentage inhibition at which the assay is considered positive. Five out of six rabbits seroconverted between 24 and 28 days post infection. (C) OvHV-2 DNA copy number was detected in peripheral blood leukocytes by real-time PCR. There was an abrupt increase in copy number between 19 and 24 days post infection. 
A

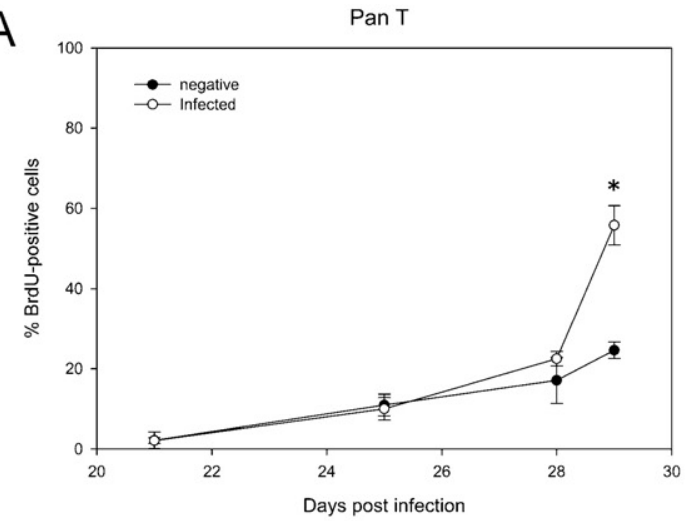

$\mathrm{CD} 8$

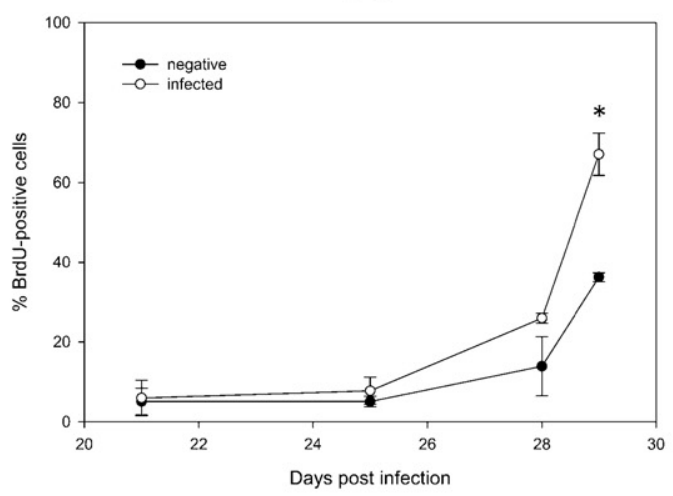

Monocytes

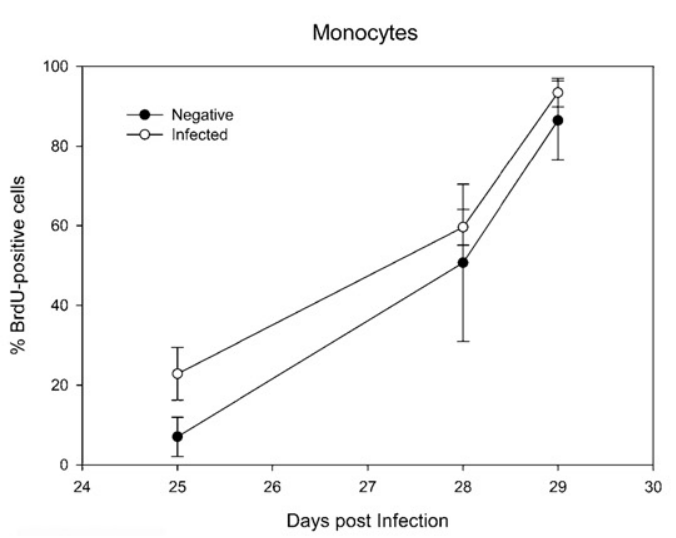

B

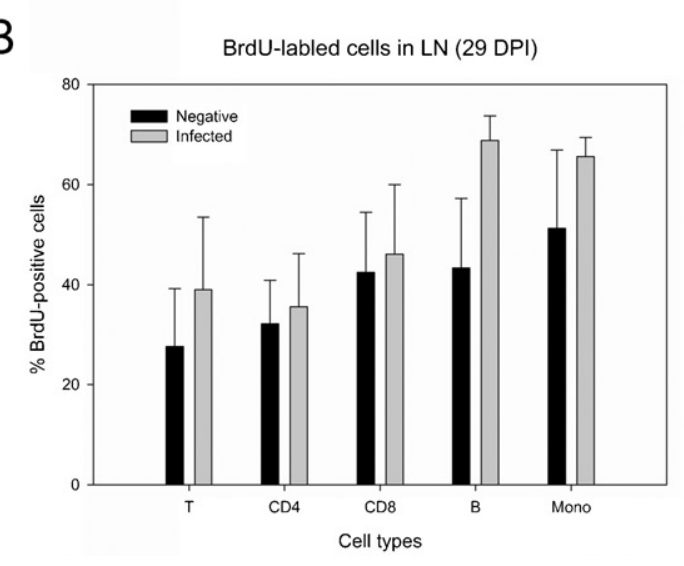

CD4

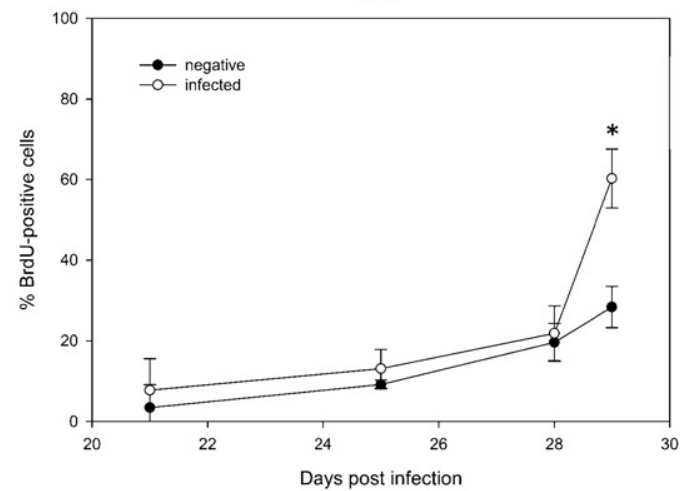

B-cells

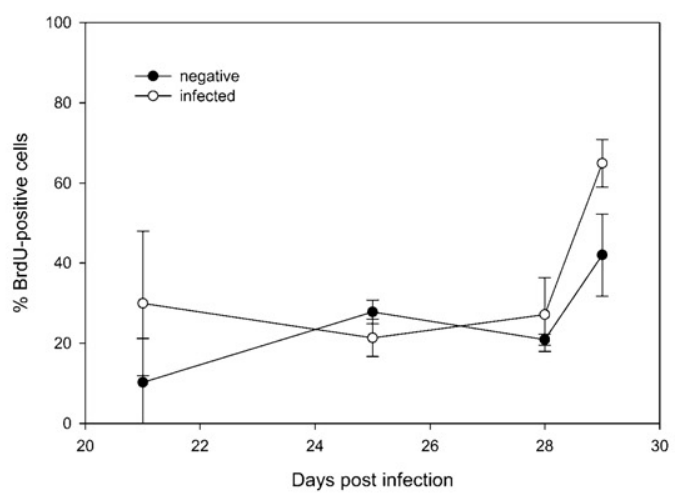

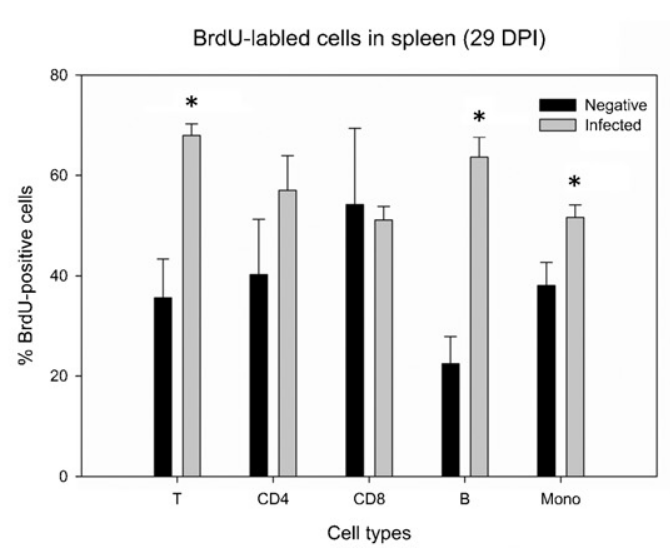


Table 1

OvHV-2 DNA, viral gene transcripts and histological lesions in selected tissues of rabbits with OvHV-2 induced MCF.

\begin{tabular}{|c|c|c|c|c|c|c|c|c|c|c|c|c|c|c|c|}
\hline \multirow[t]{3}{*}{ Animal No. } & \multicolumn{15}{|l|}{ Tissues } \\
\hline & \multicolumn{3}{|c|}{ Lymph node } & \multicolumn{3}{|l|}{ Spleen } & \multicolumn{3}{|l|}{ Lung } & \multicolumn{3}{|l|}{ Liver } & \multicolumn{3}{|c|}{ Urinary bladder } \\
\hline & $\begin{array}{l}\text { ORF } \\
25 / 50 / 73\end{array}$ & $\begin{array}{l}\text { DNA } \\
\text { copy }^{\text {a }}\end{array}$ & $\begin{array}{l}\text { Histo } \\
\text { lesion }\end{array}$ & $\begin{array}{l}\text { ORF } \\
25 / 50 / 73\end{array}$ & $\begin{array}{l}\text { DNA } \\
\text { copy }\end{array}$ & $\begin{array}{l}\text { Histo } \\
\text { lesion }\end{array}$ & $\begin{array}{l}\text { ORF } \\
25 / 50 / 73\end{array}$ & $\begin{array}{l}\text { DNA } \\
\text { copy }\end{array}$ & $\begin{array}{l}\text { Histo } \\
\text { lesion }\end{array}$ & $\begin{array}{l}\text { ORF } \\
25 / 50 / 73\end{array}$ & $\begin{array}{l}\text { DNA } \\
\text { copy }\end{array}$ & $\begin{array}{l}\text { Histo } \\
\text { lesion }\end{array}$ & $\begin{array}{l}\text { ORF } \\
25 / 50 / 73\end{array}$ & $\begin{array}{l}\text { DNA } \\
\text { copy }\end{array}$ & $\begin{array}{l}\text { Histo } \\
\text { lesion }\end{array}$ \\
\hline 1 & $+/+1+^{\mathrm{b}}$ & $4 \times 10^{6}$ & $\mathrm{n} / \mathrm{a}^{\mathrm{c}}$ & $+/+/+$ & $1 \times 10^{5}$ & $\mathrm{n} / \mathrm{a}$ & $+/+/+$ & $4 \times 10^{6}$ & $+^{\mathrm{d}}$ & $+/+/+$ & $1 \times 10^{6}$ & ++ & $+1+1-$ & $1 \times 10^{5}$ & - \\
\hline 2 & $+1+1+$ & $2 \times 10^{5}$ & $\mathrm{n} / \mathrm{a}$ & $+1+1-$ & $2 \times 10^{5}$ & $\mathrm{n} / \mathrm{a}$ & $+/+/+$ & $2 \times 10^{6}$ & + & $+/+1+$ & $8 \times 10^{5}$ & ++ & $-1-1-$ & $3 \times 10^{2}$ & - \\
\hline 3 & $+1+1+$ & $9 \times 10^{5}$ & $\mathrm{n} / \mathrm{a}$ & $+1+1+$ & $9 \times 10^{5}$ & + & $+1+1+$ & $7 \times 10^{6}$ & + & $+1+1+$ & $1 \times 10^{7}$ & +++ & $\begin{array}{l}1+1 \\
+1+-\end{array}$ & $1 \times 10^{5}$ & - \\
\hline 4 & $+1+1+$ & $2 \times 10^{5}$ & $\mathrm{n} / \mathrm{a}$ & $+1+1+$ & $1 \times 10^{5}$ & $\mathrm{n} / \mathrm{a}$ & $+1+1+$ & $5 \times 10^{6}$ & ++ & $+1+1+$ & $3 \times 10^{6}$ & ++ & $+1+1+$ & $1 \times 10^{6}$ & - \\
\hline 5 & $+1+1+$ & $6 \times 10^{5}$ & $\mathrm{n} / \mathrm{a}$ & $+1+1+$ & $1 \times 10^{6}$ & $\mathrm{n} / \mathrm{a}$ & $+1+1+$ & $7 \times 10^{6}$ & ++ & $+1+1+$ & $8 \times 10^{6}$ & +++ & $+1+1-$ & $4 \times 10^{5}$ & - \\
\hline 6 & $+1+1+$ & $1 \times 10^{6}$ & + & $+1+1+$ & $1 \times 10^{6}$ & $\mathrm{n} / \mathrm{a}$ & $+1+1+$ & $2 \times 10^{6}$ & + & $+1+1+$ & $2 \times 10^{6}$ & ++ & $+1+1+$ & $3 \times 10^{7}$ & - \\
\hline
\end{tabular}

a OvHV-2 DNA copies in 500 ng total DNA measured by real-time PCR.

b Transcripts of OvHV-2 ORF25, 50 and 73 were detected by real-time RT-PCRs (+, transcripts present; -, transcripts absent).

c Samples were not available.

${ }^{\mathrm{d}}$ Lesion severity in tissues based on histological findings (the severity is indicated by number of +; the absence of lesion is indicated by -).

cells were also proliferating in rabbits with OvHV-2 induced MCF.

\subsection{OvHV-2 DNA and transcripts detected in rabbits with OvHV-2 induced MCF}

OvHV-2 DNA levels were measured in tissues (mesenteric lymph node, spleen, liver, lung and bladder) of all clinically affected rabbits. The viral DNA was detected in all 30 samples examined with a mean copy number of $3.124 \times 10^{6}$ per $500 \mathrm{ng}$ of tissue DNA ranging from $\sim 300$ to $3 \times 10^{7}$ copies (Table 1 ). OvHV-2 ORF25, ORF50 and ORF73 transcripts were analyzed in PBL and in 5 tissues from the rabbits with OvHV-2 induced MCF. ORF25, a viral structural gene, codes for the major capsid protein during late lytic gene expression. ORF50 is an immediate-early gene that codes for a viral transactivator [homologous to Epstein-Barr virus (EBV) Rta protein] involved in control of viral transcription and reactivation from latency (Hart et al., 2007). ORF73 codes for a homolog of the gammaherpesvirus latency-associated nuclear protein, which is involved in viral genome maintenance and expressed during lytic and latent infection (Ahn et al., 2002; Gailbreath et al., 2008; Hart et al., 2007). Detection of ORF73 transcripts and not ORF25 or ORF50 transcripts would be suggestive of latency. As the results show in Table 1, the transcripts of all three genes (ORF25, ORF50 and ORF73) were detected in PBL of all rabbits euthanized within $48 \mathrm{~h}$ of clinical signs. $97 \%$ of tissue samples examined $(n=30)$ had transcripts of both ORF25 and ORF50 detected, while $83 \%$ of tissues had ORF73 transcripts, but no sample was positive only for ORF73. Urinary bladder was the tissue that had the least detectable transcripts: five out of six for OFR25 or ORF50, and two out of six for ORF73.

\section{Discussion}

Laboratory rabbits are increasingly used as experimental surrogates for MCF-susceptible members of the order Artiodactyla, including domesticated cattle, deer and American bison. They are particularly useful because of cost and convenience, and since the disease in rabbits reproduces many of the features of MCF in susceptible ruminants. These include the relatively long incubation period (2-5 weeks), many of the clinical signs, and part of the lesion spectrum. Lymphoid hyperplasia, particularly of CD8+ and other unidentified T cell subsets, is a stereotypical feature of MCF in rabbits, regardless of the route of inoculation or whether the inoculum is OvHV-2, AlHV-1 including AlHV-1 bacterial artificial chromosome (Dewals et al., 2006), or HipHV-1 (Anderson et al., 2007; Buxton and Reid, 1980; Dewals et al., 2008; Edington et al., 1979; Reid et al., 1986; Schock and Reid, 1996). Lymphoid inflammation is most evident in liver and lung (Gailbreath et al., 2008). Vasculitis involving arterioles, small and medium caliber arteries and veins, is a characteristic feature of MCF in domestic cattle and also occurs in rabbits, although it tends to be confined to lung, liver and (in some studies) kidney. Epithelial necrosis of digestive, respiratory and urinary tracts, encephalitis and panophthalmitis are major features of MCF in cattle and American bison. These changes are generally inconspicuous in rabbits with MCF. Minor differences exist in the pattern of lesions in rabbits that develop MCF due to OvHV-2, as compared to AlHV-1 (Anderson et al., 2007). Necrosis of lymphoid tissues is more marked, and lymphoid infiltration of kidney, liver and lung less extensive, in OvHV-2-infected rabbits (Gailbreath et al., 2008). Rabbits infected intra-nasally with OvHV-2 develop minimal splenomegaly, peripheral lymphadenopathy, or intra-cecal lymphoid hyperplasia

Fig. 2. In vivo BrdU incorporation in mononuclear cells of rabbits experimentally infected with OvHV-2. Rabbits in both positive and negative groups were injected intravenously daily with BrdU $(25 \mathrm{mg} / \mathrm{kg})$ at 20 days post infection until the end of experiment. PBMCs were collected at $21,25,28$, and 29 days post-inoculation, while mononuclear cells were isolated from mesenteric lymph node and spleen at the time of death (29 days post infection). Cells were labeled with anti-pan-T (RTH26A), CD4 (KEN-4), CD8 (ISC27A), B-cell (MRB29A), or monocytes/basophils (MRB120A) markers as the primary antibodies. Appropriate fluorescent-conjugated goat anti-mouse antibodies were used as the secondary antibody. In vivo BrdU incorporation was revealed by immunofluorescent staining as described in Section 2. After staining, cells were analyzed by flow cytometry. * indicates the percentage of BrdU-positive cells in infected rabbits is significantly higher than the control $(p<0.05)$. (A) The data represent the percentages of BrdU positive cells $(y$-axis) expressing different cell markers for PBMCs at different time points ( $x$-axis). (B) The data represent the percentages of BrdU positive cells ( $y$-axis) expressing the indicated cell marker ( $x$-axis) in spleen (right) and lymph node (left). Error bars represent one standard deviation of the mean. 
compared to AlHV-1 or AlHV-1 BAC challenged rabbits. Granulomatous lesions, including the presence of giant cells, were present in liver, lymph nodes and lungs in the present study, generally associated with tissue necrosis. Granulomatous inflammation is not a feature of MCF in susceptible ruminants, and is not reported in rabbits experimentally infected with AlHV-1. These differences are probably species-specific. They are unlikely to reduce the value of rabbits as a laboratory model for the disease, particularly when natural routes of exposure are used.

Although both AlHV-1 and OvHV-2 cause MCF in clinically susceptible hosts that usually are indistinguishable clinically and pathologically (Plowright, 1990), this and previous studies suggest that there might be a difference in pathogenesis between the two viruses. It has been controversial whether MCF lesion development is associated with viral latency or lytic gene expression. Since latency and lytic replication is a common feature of all herpesviruses during infection, it is not surprising that both infection states (latent and lytic) coexist at the tissue level, especially in gammaherpesviral infection. The study on rabbits with AlHV-1 induced MCF showed latency was the predominant phenomenon detected, indicated by ORF 73 transcripts in tissues (Dewals et al., 2008), which is in contrast to a lytic gene expression profile, indicated by detection of ORF25, ORF50 and ORF73 transcripts, observed in the rabbits with OvHV-2 induced MCF in the current study. An earlier study on detection of OvHV-2 structural proteins and mRNA transcripts in clinically affected rabbits using in situ methods (Meier-Trummer et al., 2009b) supports the lytic gene expression profile observed in this study. However, two putative OvHV-2 structural proteins (coded by ORF43 and ORF63 genes) and their mRNA were detected only in the appendix (MeierTrummer et al., 2009b), while the transcripts of ORFs 25, 50 and 73 were present in virtually all tissues examined in our study. Although the reason for the difference between the two studies is not completely clear, this could be due to the inoculation routes (nasal vs. intramuscular) and the forms of inoculum (cell-free vs. cell-associated). This also could be due to the test sensitivities (in situ methods vs. RT-PCR). Moreover, the OvHV-2 gene expression in clinically affected rabbits in this study was consistent with our findings in bison and cattle with experimentally induced MCF (Cunha et al., 2007), but in contrast with previously published data indicating that only ORF73 transcripts were detected in the lymph nodes of cattle with naturally acquired sheep-associated MCF (Meier-Trummer et al., 2009a). The reason for the discrepancy is not clear. Several factors, such as the sensitivity of detection methods, levels of expression in different hosts and tissues, individual susceptibility, and the disease stages could contribute to the different outcomes. Additional studies are definitely needed to evaluate the differences among the studies.

Interpretation of in vivo BrdU assays is somewhat difficult (Bonhoeffer et al., 2000). In order to have a better comparison of lymphoproliferation in rabbits with MCF resulting from AlHV-1 and OvHV-2, we adapted the same protocol that was used in the AlHV-1 study (Dewals et al., 2008). A difference in lymphoproliferation was found in rabbits with clinical MCF: only CD8+ cell proliferation was observed in rabbits with AlHV-1 induced MCF (Dewals et al., 2008), while both T cells (including CD8 and CD4) (in peripheral blood) and $\mathrm{B}$ cells (in spleen) proliferated in rabbits with OvHV-2 induced MCF. The reason why the proliferation was not uniformly detected in peripheral blood and lymphoid tissues (LN and spleen) is not understood. It could be due to insufficient BrdU in the system, since the injection of BrdU started at $20 \mathrm{DPI}$; it also could be due to slower cell proliferation in OvHV-2 infected rabbits. Additional studies are needed to answer these questions. Taken together, the data from this study strongly suggest that AlHV-1 and OvHV-2 are likely to play a different role in pathogenesis of MCF.

This was the second experimental induction of MCF in rabbits by aerosol transmission of OvHV-2 from sheep nasal secretions, a route of inoculation mimicking natural transmission. The success rate in this experiment for induction of MCF in rabbits was $100 \%$ with all six rabbits developing the disease between 20 and 27 days post infection. In the first experiment, only 5 out of 8 rabbits developed MCF using the same viral dose and the same procedure (Gailbreath et al., 2008), giving a 60\% success rate. The reason for this difference is unclear. Ages of rabbits in both experimental groups were similar and the weights were not significantly different (the first group: $6.86 \mathrm{lb} \pm 0.33$; the second group: $7.21 \pm 0.42$ ). One explanation may be due to the difference in breeding programs between the two rabbit suppliers (the first group has a strictly outbred program; the second group has a highly inbred program). Regardless of whether inbreeding can result in increasing the susceptibility to MCF in rabbits, caution should be taken when choosing rabbit suppliers.

In summary, MCF can be induced in $100 \%$ of rabbits, using nebulization that mimics the natural route of transmission with an acceptable amount of OvHV-2 inoculum. The characteristics of disease in rabbits with OvHV-2 induced MCF include pan lymphoproliferation and expression of OvHV-2 lytic cycle genes at the clinical stage, which are different from those in rabbits with AlHV-1 induced MCF. Additional studies are needed to determine whether OvHV-2 replication and host immune response to the replication in rabbits are the same or similar to those in bison. There is no doubt that rabbits are a practical, costeffective alternative for carefully designed MCF studies that would be difficult or impossible to perform in bison or cattle.

\section{Acknowledgements}

This work was supported by USDA-ARS CWU 534832000-024-00D. We thank Jan Keller, Shirley Elias, Lori Fuller, and Emma Karel for technical assistance and animal care and Lindsay Oaks for valuable discussion.

\section{References}

Ahn, J.W., Powell, K.L., Kellam, P., Alber, D.G., 2002. Gammaherpesvirus lytic gene expression as characterized by DNA array. J. Virol. 76, 6244-6256.

Anderson, I.E., Buxton, D., Campbell, I., Russell, G., Davis, W.C., Hamilton, M.J., Haig, D.M., 2007. Immunohistochemical study of experimental malignant catarrhal fever in rabbits. J. Comp. Pathol. 136, 156-166. 
Anscombe, F.J., 1948. The transformation of Poisson, binomial, and negative-binomial data. Biometrika 35, 246-254.

Audige, L., Wilson, P.R., Morris, R.S., 1994. Deer herd health and production profiling in New Zealand. 2. Preliminary results. Int. Symp. Ecopathol. Anim. Health Manage. 25, 258-262.

Baxter, S.I.F., Pow, I., Bridgen, A., Reid, H.W., 1993. PCR detection of the sheep-associated agent of malignant catarrhal fever. Arch. Virol. 132, 145-159.

Bedelian, C., Nkedianye, D., Herrero, M., 2007. Maasai perception of the impact and incidence of malignant catarrhal fever (MCF) in southern Kenya. Prev. Vet. Med. 78, 296-316.

Bonhoeffer, S., Mohri, H., Ho, D., Perelson, A.S., 2000. Quantification of cell turnover kinetics using 5-bromo-2'-deoxyuridine. J. Immunol. 164, 5049-5054.

Blake, J.E., Nielsen, N.O., Heuschele, W.P., 1990. Lymphoproliferation in captive wild ruminants affected with malignant catarrhal fever: 25 cases (1977-1985). J. Am. Vet. Med. Assoc 196, 1141-1143.

Buxton, D., Reid, H.W., 1980. Transmission of malignant catarrhal fever to rabbits. Vet. Rec. 106, 243-245.

Cunha, C.W., Traul, D.L., Taus, N.S., Oaks, J.L., O’Toole, D., Davitt, C.M., Li, H., 2007. Detection of ovine herpesvirus 2 major capsid gene transcripts as an indicator of virus replication in shedding sheep and clinically affected animals. Virus Res. 132, 69-75.

Daniels, P.W., Sudarisman, Ronohardjo, P., 1988. Malignant Catarrhal Fever in Asian Livestock. , p. 129

Davis, W.C., Hamilton, M.J., 2008. Use of flow cytometry to develop and characterize a set of monoclonal antibodies specific for rabbit leukocyte differentiation molecules. J. Vet. Sci. 9, 51-66.

Davison, A.J., Eberle, R., Ehlers, B., Hayward, G.S., McGeoch, D.J., Minson, A.C., Pellett, P.E., Roizman, B., Studdert, M.J., Thiry, E., 2009. 2009. The order Herpesvirales. Arch. Virol. 154, 171-177.

Dewals, B., Boudry, C., Farnir, F., Drion, P.V., Vanderplasschen, A., 2008. Malignant catarrhal fever induced by alcelaphine herpesvirus 1 is associated with proliferation of CD8 $\mathrm{T}$ cells supporting a latent infection. PLoS ONE 3, e1627.

Dewals, B., Boudry, C., Gillet, L., Markine-Goriaynoff, N., de, L.L., Haig, D.M., Vanderplasschen, A., 2006. Cloning of the genome of Alcelaphine herpesvirus 1 as an infectious and pathogenic bacterial artificial chromosome. J. Gen. Virol. 87, 509-517.

Edington, N., Patel, J., Russell, P.H., Plowright, W.. 1979. The nature of the acute lymphoid proliferation in rabbits infected with the herpes virus of bovine malignant catarrhal fever. Eur. J. Cancer. 15, 1515-1522.

Gailbreath, K.L., Taus, N.S., Cunha, C.W., Knowles, D.P., Li, H., 2008. Experimental infection of rabbits with ovine herpesvirus 2 from sheep nasal secretions. Vet. Microbiol. 132, 65-73.

Haig, D.M., Grant, D., Deane, D., Campbell, I., Thomson, J., Jepson, C., Buxton, D., Russell, G.C., 2008. An immunisation strategy for the protection of cattle against alcelaphine herpesvirus-1-induced malignant catarrhal fever. Vaccine 26, 4461-4468.

Hart, j., Ackermann, M., Jayawardane, G., Russell, G., Haig, D.M., Reid, H., Stewart, J.P., 2007. Complete sequence and analysis of the Ovine herpesvirus 2 genome. J. Gen. Virol. 88, 28-39.

Heuschele, W.P., 1988. Malignant catarrhal fever: a review of a serious disease hazard for exotic and domestic ruminants. Zool. Garten. 58, 123.

Li, H., Cunha, C.W., Davies, C.J., Gailbreath, K.L., Knowles, D.P., Oaks, J.L., Taus, N.S., 2008. Ovine herpesvirus 2 replicates initially in the lung of experimentally infected sheep. J. Gen. Virol. 89, 1699-1708.

Li, H., Gailbreath, K., Flach, E.J., Taus, N.S., Cooley, J., Keller, J., Russell, G.C., Knowles, D.P., Haig, D.M., Oaks, J.L., Traul, D.L., Crawford, T.B., 2005. A novel subgroup of rhadinoviruses in ruminants. J. Gen. Virol. 86, 3021-3026.

Li, H., McGuire, T.C., Muller-Doblies, U.U., Crawford, T.B., 2001. A simpler, more sensitive competitive inhibition ELISA for detection of antibody to malignant catarrhal fever viruses. J. Vet. Diagn. Invest. 13, 361-364.

Li, H., Shen, D.T., Knowles, D.P., Gorham, J.R., Crawford, T.B., 1994. Competitive inhibition enzyme-linked immunosorbent assay for antibody in sheep and other ruminants to a conserved epitope of malignant catarrhal fever virus. J. Clin. Microbiol. 32, 1674-1679.

Li, H., Shen, D.T., O’Toole, D.T., Knowles, D.P., Gorham, J.R., Crawford, T.B., 1995. Investigation of sheep-associated malignant catarrhal fever virus infection in ruminants by PCR and competitive inhibition enzyme-linked immunosorbent assay. J. Clin. Microbiol. 33, 20482053.

Li, H., Taus, N.S., Jones, C., Murphy, B., Evermann, J.F., Crawford, T.B., 2006. A devastating outbreak of malignant catarrhal fever in a bison feedlot. J. Vet. Diagn. Invest. 18, 119-123.

Li, H., Taus, S.N., Lewis, G.S., Kim, O., Traul, D.L., Crawford, T.B., 2004. Shedding of ovine herpesvirus 2 in sheep nasal secretions: the predominant mode for transmission. J. Clin. Microbiol. 42, 5558-5564.

Liggitt, H.D., DeMartini, J.C., 1980a. The pathomorphology of malignant catarrhal fever. I. Generalized lymphoid vasculitis. Vet. Pathol. 17. 58-72.

Liggitt, H.D., DeMartini, J.C., 1980b. The pathomorphology of malignant catarrhal fever. II. Multisystemic epithelial lesions. Vet. Pathol. 17, 73-83.

Mamo, S., Gal, A.B., Polgar, Z., Dinnyes, A., 2008. Expression profiles of the pluripotency marker gene POU5F1 and validation of reference genes in rabbit oocytes and preimplantation stage embryos. BMC Mol. Biol. $9,67$.

Meier-Trummer, C.S., Rehrauer, H., Franchini, M., Patrignani, A., Wagner, U., Ackermann, M., 2009a. Malignant catarrhal fever of cattle is associated with low abundance of IL-2 transcript and a predominantly latent profile of ovine herpesvirus 2 gene expression. PLoS ONE 4, e6265.

Meier-Trummer, C.S., Tobler, K., Hilbe, M., Stewart, J.P., Hart, j., Campbell, I., Haig, D.M., Glauser, D.L., Ehrensperger, F., Ackermann, M., 2009b. Ovine herpesvirus 2 structural proteins in epithelial cells and M-cells of the appendix in rabbits with malignant catarrhal fever. Vet. Microbiol. 137, 235-242.

Meteyer, C.U., Gonzales, B.J., Heuschele, W.P., Howard, E.B., 1989. Epidemiologic and pathologic aspects of an epizootic of malignant catarrhal fever in exotic hoofstock. J. Wildl. Dis. 25, 280-286.

Mushi, E.Z., 1980. The proliferation of malignant catarrhal fever virus in cattle and rabbits. Bull. Anim. Health Prod. Afr. 28, 85-89.

Mushi, E.Z. Rurangirwa, F.R., Karstad, L., 1981. Shedding of malignant catarrhal fever virus by wildebeest calves. Vet. Microbiol. 6, 281-286.

O'Toole, D., Li, H., Sourk, C., Montgomery, D.L., Crawford, T.B., 2002. Malignant catarrhal fever in a bison feedlot, 1993-2000. J. Vet. Diagn. Invest. 14, 183-193.

O'Toole, D., Taus, D.N., Montgomery, D.L., Oaks, J.L., Crawford, T.B., Li, H., 2007. Intra-nasal inoculation of American bison (Bison bison) with OvHV-2 reliably reproduces malignant catarrhal fever. Vet. Pathol. 44, 655-662.

Orr, M.B., Mackintosh, C.G., 1988. An outbreak of malignant catarrhal fever in Pere David's deer (Elaphurus davidianus). N. Z. Vet. J. 36, $19-21$.

Plowright, W., 1990. Malignant catarrhal fever virus. Malignant catarrhal fever virus. In: Dinter, Z., Morein, B. (Eds.), Virus Infections of Ruminants. Elsevier Science Publishers, New York, pp. 123-150.

Reid, H.W., Buxton, D., Pow, I., Finlayson, J., 1986. Malignant catarrhal fever: experimental transmission of the 'sheep-associated' form of the disease from cattle and deer to cattle, deer, rabbits and hamsters. Res. Vet. Sci. 41, 76-81.

Russell, G.C., Stewart, J.P., Haig, D.M., 2009. Malignant catarrhal fever: a review. Vet. J. 179, 324-335.

Schock, A., Reid, H.W., 1996. Characterisation of the lymphoproliferation in rabbits experimentally affected with malignant catarrhal fever. Vet. Microbiol 53, 111-119.

Schultheiss, P.C. Collins, J.K., Spraker, T.R., DeMartini, J.C., 2000. Epizootic malignant catarrhal fever in three bison herds: differences from cattle and association with ovine herpesvirus-2. J. Vet. Diagn. Invest. 12, 497-502.

Traul, D.L., Taus, N.S., Oaks, J.L., O’Toole, D., Rurangirwa, F.R., Baszler, T.V., Li, H., 2007. Validation of nonnested and real-time PCR for diagnosis of sheep-associated malignant catarrhal fever in clinical samples. J. Vet. Diagn. Invest. 19, 405-408.

Wiyono, A., Baxter, S.I.F., Saepulloh, M., Damayanti, R., Daniels, P., Reid, H.W., 1994. PCR detection of ovine herpesvirus-2 DNA in Indonesian ruminants - normal sheep and clinical cases of malignant catarrhal fever. Vet. Microbiol. 42, 45-52. 